\title{
Efficacy of Er,Cr:YSGG Laser with ConicalTip Design in Smear Layer Removal at the Apical Third of Curved Root Canals
}

\author{
M Sabari Murugesan, M Rajasekaran, R Indra, Premila Suganthan
}

\begin{abstract}
This ex vivo study investigates the effectiveness of the new design of the tip of $\mathrm{Er}, \mathrm{Cr}$ :YSGG laser (BIOLASE ${ }^{\mathrm{TM}}$ ) in removing the smear layer at the apical third of curved root canals. Eighty one freshly extracted intact single rooted human mandibular premolar teeth with $15^{\circ}$ to $30^{\circ}$ canal curvature were selected and decoronated at the level of the cementoenamel junction. The roots were divided into three main groups with 27 samples each. Group I-non-lased teeth, group II-teeth lased with plain tip and group III-teeth lased with conical tip. Each group was further divided into three subgroups of nine samples each with $2 \mathrm{ml}$ of $17 \%$ (Ethylene diamine tetraacetic acid (EDTA), $2 \mathrm{ml}$ of $2 \%$ chlorhexidine ( $\mathrm{CHX}), 2 \mathrm{ml}$ of $3 \%$ sodium hypochlorite $(\mathrm{NaOCl})$ respectively. In all the three groups, canals were prepared with rotary nickel-titanium (NiTi) instruments to a working length $1 \mathrm{~mm}$ short of the apex to size F3, using ProTaper instruments. The fiber tips were placed into the appropriate irrigant solution in the root canal to a depth of $1 \mathrm{~mm}$ short of working length and then activated for 20 seconds. The teeth were split longitudinally and subjected to scanning electron microscopy (SEM) at $1000 \times$. It can be concluded that to ensure complete removal of smear layer from the root canal system it may be prudent to activate EDTA with conical tip design of Er,Cr:YSGG laser during irrigation protocol in the curved root canals.
\end{abstract}

Keywords: Er,Cr:YSGG laser, Conical tip design, Curved root canals, Smear layer, Scanning electron microscope.

How to cite this article: Murugesan MS, Rajasekaran M, Indra $R$, Suganthan P. Efficacy of Er,Cr:YSGG Laser with Conical Tip Design in Smear Layer Removal at the Apical Third of Curved Root Canals. Int J Laser Dent 2013;3(2):55-59.

\section{Source of support: Nil}

Conflict of interest: None declared

\section{INTRODUCTION}

The success of root canal treatment depends on the root canal system being thoroughly cleansed and disinfected, followed by the adequate obturation of this space. ${ }^{1}$ After chemomechanical preparation, the smear layer is formed covering the dentinal walls and the deeper portion of this smear layer is packed into the dentinal tubules up to $40 \mu$. $^{2}$

There is lack of consistency in reports pertaining to the removal of smear layer by using lasers delivered with conventional (forward-firing) optical fibers. ${ }^{3}$ A recent study in the literature reveals that conical-ended fiber tip with lateral emission was found to perform well for lasers used in endodontics and gives better control of fiber shape than other methods, such as polishing or heating and pulling. Such conical-ended fibers also provide improved debriding actions in the root canal when used to deliver energy from a water absorbing middle infrared laser (Er,Cr:YSGG) into an aqueous irrigant, because absorption of laser energy would induce shock waves into the irrigant. ${ }^{4,5}$

The aim of this ex vivo study was to investigate the effectiveness of newer tip design of Er,Cr:YSGG laser in removing the smear layer at the apical third of curved root canals.

\section{MATERIALS AND METHODS}

\section{Experimental Design}

A total of 81 intact single rooted human mandibular premolars extracted for orthodontic reasons were collected and stored in water containing $0.1 \%$ thymol until needed for the study. The teeth were cleaned ultrasonically for removing calculus and debris. Roots of mandibular premolars having curvature more than $15^{\circ}$ to $30^{\circ}$ (curvature determined by radiograph) were selected. The degree of canal curvature was determined for each tooth using the Schneider method. The teeth were then decoronated at the cement-enamel junction using a diamond disk under water spray.

\section{Canal Preparation}

The working length was determined by measuring the length of \#10 K-file passively inserted into the canal until it was visible at the apex and then backing off $1 \mathrm{~mm}$. Canals were prepared with rotary protaper instruments to a working length $1 \mathrm{~mm}$ short of the apex to size F3. Irrigation of all the samples during preparation was accomplished using a combination of $2 \mathrm{ml}$ of $17 \%$ EDTA and $2 \mathrm{ml}$ of $3 \%$ sodium hypochlorite solution. All irrigants were delivered with a 23-gauge needle. Final rinse was done with distilled water $(10 \mathrm{ml})$ in all the canals using disposable syringe and needle to prevent chemical interaction between the irrigants.

\section{Laser Parameters}

The Waterlase MD laser (Biolase) was used at panel settings of $1.25 \mathrm{~W}$ average power and $20 \mathrm{~Hz}(62.5 \mathrm{~mJ} /$ pulse) (Figs $1 \mathrm{~A}$ and B) and was delivered into a $300 \mu \mathrm{m}$ (size ISO 30) endodontic fiber with either plain or conical tips (Figs 2 and 3). No air or water spray was used. The fiber tip 


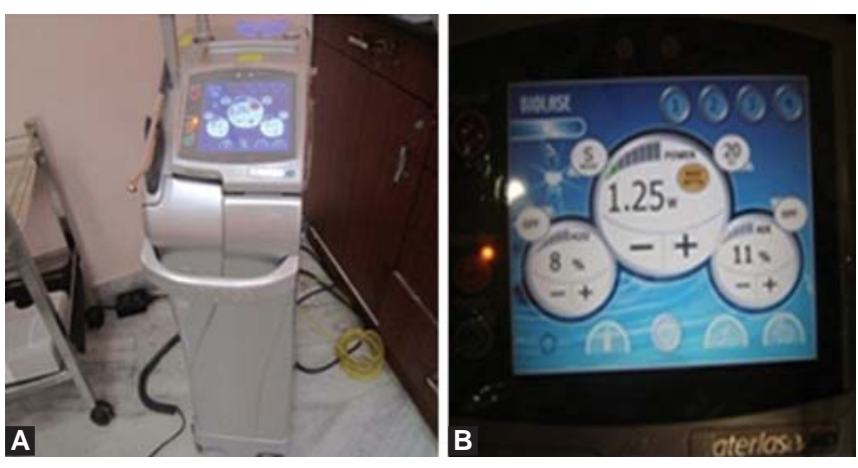

Figs 1A and B: (A) Er,Cr:YSGG laser (Biolase ${ }^{\mathrm{TM}}$ Waterlase MD), (B) panel setting [1.25 W average power and $20 \mathrm{~Hz}(62.5 \mathrm{~mJ} /$ pulse $)]$
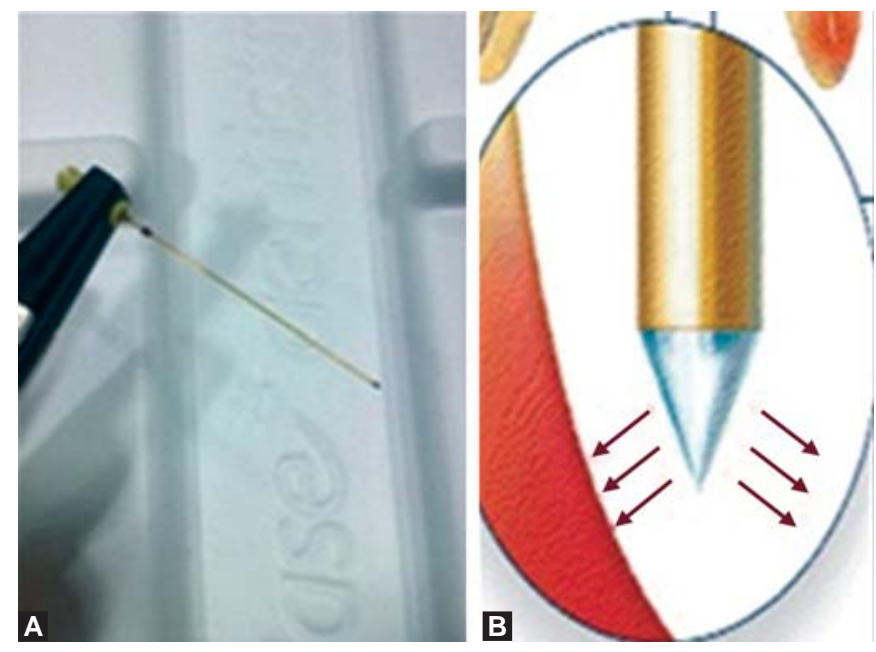

Figs 2A and B: Conical fiber tip (RFT 3 Biolase, Irvine, CA)

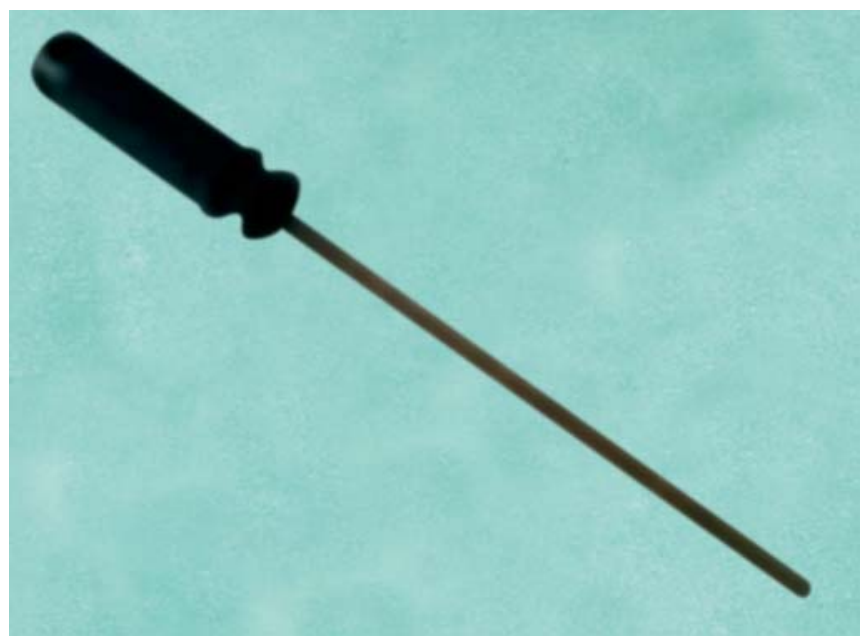

Fig. 3: Plain fiber tip ( $M Z$ 3, Biolase, Irvine, $C A)$

was fixed in the hand-piece of an Erbium-Chromium:Yttrium Scandium-Gallium-Garnet (Er,Cr:YSGG) lasers.

\section{Experimental Groups}

A total of 81 teeth were randomly divided into three groups of 27 specimens each which in turn further divided into three subgroups each containing nine teeth.

\section{Main Groups}

Group I: Nonlased teeth

Group II: Teeth lased with plain tip

Group III: Teeth lased with conical tip.

\section{Subgroups: Irrigants}
A: $17 \%$ EDTA (2 ml)
B: $2 \% \mathrm{CHX}(2 \mathrm{ml})$
C: $3 \% \mathrm{NaOCl}(2 \mathrm{ml})$

\section{DISTRIBUTION OF SAMPLES}

\section{Group I: Irrigants not activated by Laser (Nonlased Teeth)}

The canal was irrigated with 17\% EDTA ( $2 \mathrm{ml}$ ), 3\% NaOCl $(2 \mathrm{ml})$ and $2 \%$ chlorhexidine ( $2 \mathrm{ml}$ ) for 2 minutes in the respective subgroups. Laser activation was not done in this group.

\section{Group II: Irrigants activated by Er,Cr:YSGG Laser with Plain Tip}

Plain laser fiber tip was placed into the appropriate irrigant solution in the root canal to a depth $1 \mathrm{~mm}$ short of the working length and then activated for 5 seconds. Only the apical third of the root canal system was treated. Immediately after lasing, $1 \mathrm{ml}$ of irrigant was flushed into the canal for a period of 5 seconds. Lasing was then repeated for a total of four cycles of irrigation.

\section{Group III: Irrigants activated by Er,Cr:YSGG Laser with Conical Tip}

Conical Laser fiber tip was placed into the appropriate irrigant solution in the root canal to a depth $1 \mathrm{~mm}$ short of the working length and then activated for 5 seconds. Only the apical third of the root canal system was treated. Immediately after lasing, $1 \mathrm{ml}$ of irrigant was flushed into the canal for a period of 5 seconds. Lasing was then repeated for a total of four cycles of irrigation.

\section{SEM Examination}

Roots were dried for 24 hours at room temperature and then grooved longitudinally on their buccal and lingual surfaces by using a diamond disk without water spray, with care being taken not to perforate into the canal. A chisel was placed into one of the grooves and then twisted gently to split the root into two parts. Split specimens gold sputtered and subjected to SEM evaluation. The entire area $2 \mathrm{~mm}$ from the apex was examined in each sample. The magnification used for smear layer analysis was $1000 \times$. One 


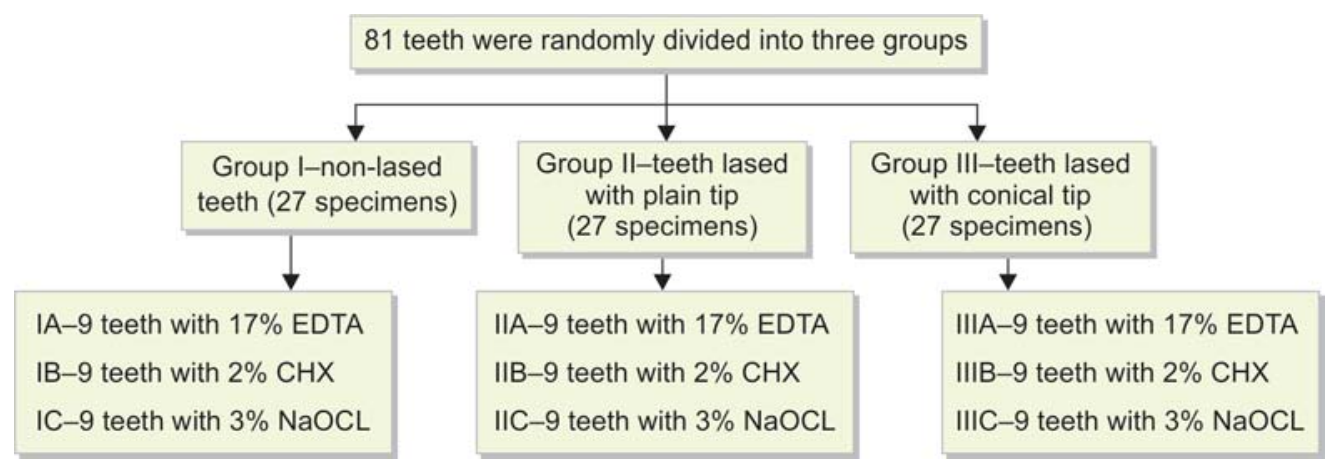

representative SEM image at this magnification was recorded at a fixed distance of $2 \mathrm{~mm}$ from the working length for each sample. Images were recorded digitally in lossless TIFF format.

\section{Scoring System}

Smear layer on the canal wall was evaluated using Torabinejad scoring system: score 1 -no smear layer-no smear layer on the surface of the canal; all tubules were clean and open. Score 2-moderate smear layer-no smear layer on the surface of the canal, but tubules contained debris (smear plug). Score 3-heavy smear layer-smear layer covered the root canal surface and the tubules.

\section{RESULTS}

The results of the present study were subjected to statistical analysis to interpret the significant differences in smear layer scores within each group and also between the groups using one-way ANOVA and post-hoc Tukey tests. There was some degree of smear layer removal with both the tips used. In the nonirradiated group (group 1), the presence of $17 \%$ EDTA as an irrigant in the canal for 20 seconds gave the modest level of smear layer removal without additional laser treatment in the apical third region when compared with CHX and $\mathrm{NaOCl}$ (Table 1).

Considering the independent variables (Table 2), the conical fiber design performed better than plain fibers in the apical third region when matched for the same irrigant used. In fact, the conical tip used with any of the three irrigants gave smear layer removal. EDTA was better than both CHX and $\mathrm{NaOCl}$ when matched for the same fiber design.

\begin{tabular}{|c|c|c|c|}
\hline \multirow[t]{2}{*}{ Groups } & \multicolumn{3}{|c|}{$p$-value } \\
\hline & $17 \%$ EDTA & $2 \% \mathrm{CHX}$ & $3 \% \mathrm{NaOCl}$ \\
\hline Group I vs group II & 0.350 & 0.083 & 0.471 \\
\hline Group I vs group III & $0.000 * *$ & $0.007^{* *}$ & 0.064 \\
\hline Group II vs group III & $0.001^{\star *}$ & 0.509 & 0.471 \\
\hline
\end{tabular}

**Denotes significance at $1 \%$ confidence level
Table 2: Post hoc Tukey analysis for intragroup comparison of smear layer scores

\begin{tabular}{lccc}
\hline Groups & \multicolumn{3}{c}{$p$-value } \\
\cline { 2 - 4 } & Group I & Group II & Group III \\
\hline 17\% EDTA vs 2\% CHX & 0.175 & 0.885 & $0.004^{\star *}$ \\
$17 \%$ EDTA vs 3\% NaOCl & 0.175 & 0.350 & $0.000^{\star *}$ \\
$2 \%$ CHX vs 3\% NaOCl & 1.000 & 0.619 & 0.640
\end{tabular}

**Denotes significant at $1 \%$ confidence level

\section{DISCUSSION}

The ability to successfully treat and remove the smear layer and bacteria continues to be a challenge in nonsurgical endodontic treatment of the root canal system. ${ }^{6}$ In contemporary endodontic practice, dual irrigants, such as Sodium Hypochlorite $(\mathrm{NaOCl})$ with Ethylenediaminetetraacetic acid (EDTA) or Chlorhexidine (CHX), are often used as initial and final rinses to complement the shortcomings that are associated with the use of a single irrigant. $^{7}$

Laser applications that use different wavelengths have also been proposed as adjuncts to conventional endodontic cleaning procedures. ${ }^{8}$ The Er,Cr:YSGG laser has a $2790 \mathrm{~nm}$ wavelength delivered by flexible fiberoptic tips was introduced, and this laser wavelength has highest absorption in water and high affinity to hydroxyapatite which makes it suitable for use in root canal therapy. ${ }^{9}$ Water or other irrigants are used during lasing to reduce thermal stress to the radicular dentin and periodontium. ${ }^{10}$

Previously, lasers were equipped with short rigid sapphire probes that were unable to access the entire length of the root canal system. Recently, thinnest small diameter commercially available Germanium-doped silica glass optical fiber tips, which may either be plain ended and conical ended, are used to negotiate the root canal system to the apical third. ${ }^{11}$

Laser treatments have the ability to remove the smear layer. This can be attributed to the ability of the laser driven irrigation used to create cavitation which results in the formation of large elliptical bubbles. These vapor bubbles can cause an expansion in volume to 1600 times the original 
volume. This process can allow the irrigants to access the apical third of the canal more easily, which might assist in the cleaning of canals of various shapes. In addition, the cavitation bubbles expand, become unstable, and then collapse in what is termed an implosion. The implosion will have an impact on the surfaces of the root canal, causing shear forces, surface deformation and the removal of surface material.

According to the present study, EDTA activated by Er,Cr:YSGG laser with conical tip showed better smear layer removal when compared to EDTA activated by Er,Cr:YSGG laser with the plain tip and the nonlased group (Table 2) (Figs 4A to C). The results of present study are in accordance with previous study by Roy George et al. who reported that laser activation of EDTA and better performance of conical fiber tip compared to plain fiber tip for improving the action of EDTA in dissolving smear layer. ${ }^{12}$

According to the present study, group II showed no significant improvement for smear layer removal in the apical third of the root canal (Figs 5A to C). The results of present study are in accordance with Dewsnup et al. who have reported that the plain fiber tip emitted laser beam in which the active cutting energy is directed parallel to the canal walls rather than laterally. This makes it difficult to control the direction of the energy beam inside the canal as described above.

Group III showed an improvement for the smear layer removal in the apical third of the root canal when compared with the group II (Figs 6A to C). These results corroborate with previous study which indicated that conical fiber tip emitted laser beam in which the active cutting energy is directed laterally to the canal walls and have lateral collection of light and are used for severely curved canals and canals with multiple curvatures. ${ }^{11}$

The present study revealed that the irrigants activated by Er,Cr:YSGG laser-conical tip performed better in the smear layer removal compared to plain tip activation of irrigants. Among the irrigants used, EDTA showed better effectiveness in smear layer removal followed by CHX and $\mathrm{NaOCl}$ in the apical third of the curved root canal system.

\section{CONCLUSION}

Within the limitations of this study, it can be concluded that:

1. Er,Cr:YSGG laser with conical fiber tip performed, better removal of smear layer in the apical third of the curved root canal system.

2. Conical fiber tip performed better than plain fiber tip for removing smear layer in the apical third of the curved root canal system.

3. Among the irrigants used, EDTA showed better effectiveness in smear layer removal followed by CHX and $\mathrm{NaOCl}$ in the apical third of the curved root canal system.

This suggests that to ensure complete removal of smear layer from the root canal system it may be prudent to activate
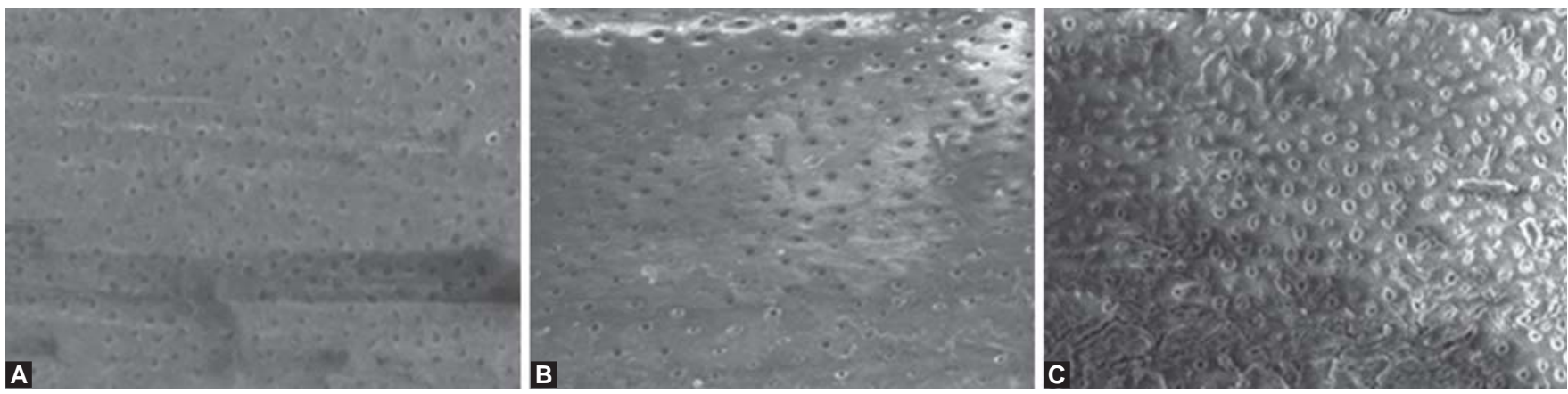

Figs 4A to C: SEM images from conical laser fiber tip groups. The root canal surface shows effective removal of the smear layer (group III): (A) EDTA, (B) $\mathrm{CHX},(\mathrm{C}) \mathrm{NaOCl}$
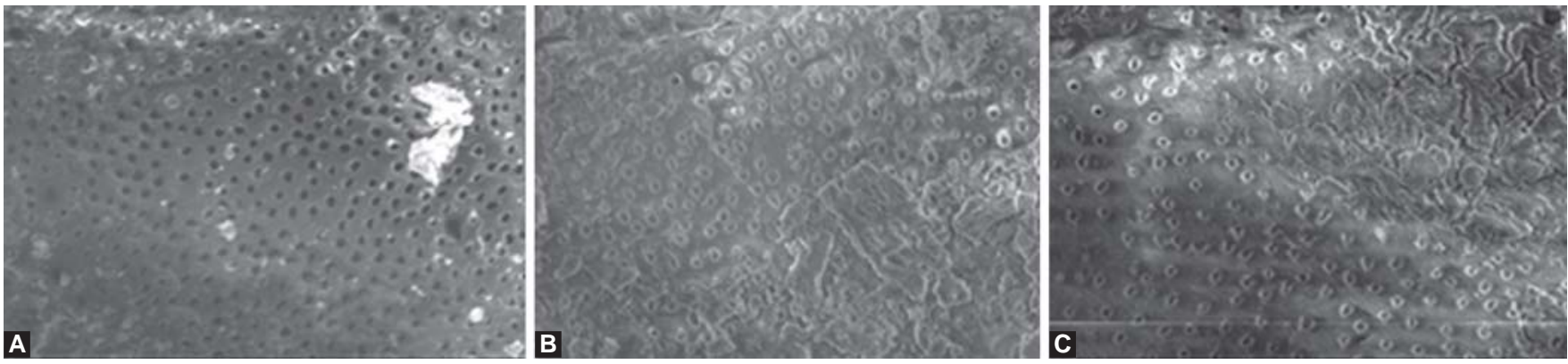

Figs 5A to C: SEM (1000x) images from plain laser fiber tip groups. The canal surface shows open tubules, residual debris and a smear layer still present (group II): (A) EDTA, (B) CHX, (C) NaOCl 

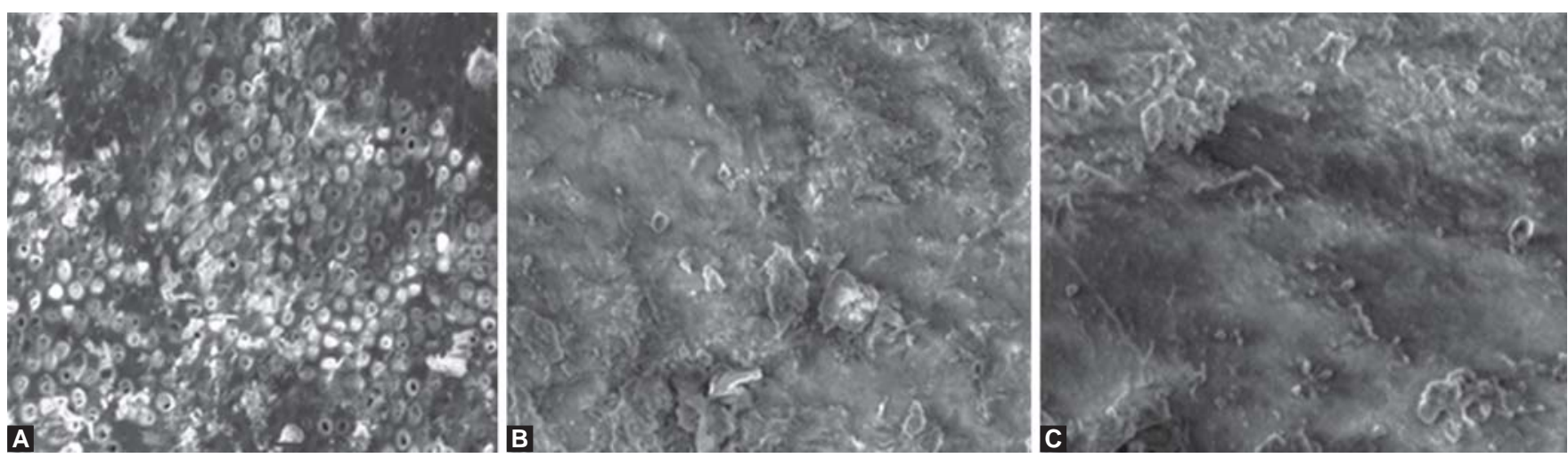

Figs 6 A to C: SEM (1000x) images from nonlasing groups. The canal surface shows a noticeable smear layer and occluded dentinal tubules (group I): (A) EDTA, (B) $\mathrm{CHX},(\mathrm{C}) \mathrm{NaOCl}$

EDTA with conical tip design of Er,Cr:YSGG laser during irrigation protocol in the curved root canals.

\section{ACKNOWLEDGMENT}

The authors gratefully thank Mr Srinivasan (Senior Technical Officer) of electron microscopy section of Anna University, Chennai, Tamil Nadu, India.

\section{REFERENCES}

1. Takeda FH, Harashima T, Kimura Y, Matsumoto K.A comparative study of the removal of smear layer by three endodontic irrigants and two types of laser. Int Endod J 1999;32:32-39.

2. Mi MY, Won-Jun S. Effect of final irrigation regimen on sealer penetration in curved root canals. J Endod 2010;36:732-736.

3. Altundasar E, Ozcelik B, Cehreli ZC, Matsumoto K. Ultramorphological and histochemical changes after Er,Cr:YSGG laser irradiation and two different irrigation regimes. J Endod 2006;32:465-468.

4. George R, Meyers IA, Walsh LJ. Laser activation of endodontic irrigants using improved conical laser fiber tips for removing smear in the apical third of the root canal. J Endod 2008;34:15241527.

5. Walsh LJ. The current status of laser applications in dentistry. Australian Dent J 2003;48:146-155.

6. DiVito E, Peters OA, Olivi G. Effectiveness of the erbium:YAG laser and new design radial and stripped tips in removing the smear layer after root canal instrumentation. Lasers Medicine Science 2010;22:142-150.

7. Gu LS, Kim Jr, Ling J. Review of contemporary irrigant agitation techniques and devices. J Endod 2009;35:791-804.

8. Huiz PH, Ketut S. Efficacy of smear layer removal at the root tip by using ethylene diaminetetraacetic acid and erbium, chromium: yttrium, scandium, gallium garnet laser. J Endod 2011;37;1585-1595.
9. Nathan D, Roberta P. Comparison of bacterial reduction in straight and curved canals using erbium, chromium:yttriumscandium-gallium-garnet laser treatment versus a traditional irrigation technique with sodium hypochlorite. J Endod 2010;36:725-728.

10. George R, Walsh LJ. Apical extrusion of root canal irrigants when using Er:YAG and Er, Cr:YSGG lasers with optical fibers: an in vitro dye study. J Endod 2008;34:706-708.

11. HoQuan, Roy G. Laser fluorescence assessment of the root canal using plain and conical optical fibers. J Endod 2010;36: 119122.

12. DiVito E, Colonna M. The photoacoustic efficacy of an Er:YAG laser with radial and stripped tips on root canal dentin walls: An sem evaluation. J Laser Dent 2011;19:156-161.

\section{ABOUT THE AUTHORS}

\section{Sabari Murugesan (Corresponding Author)}

Senior Lecturer, Department of Conservative Dentistry and Endodontics, Ragas Dental College and Hospital, Chennai, Tamil Nadu, India, Phone: 9843745412, e-mail: m_sabari82@yahoo.com

\section{Rajasekaran}

Professor, Department of Conservative Dentistry and Endodontics Ragas Dental College, Chennai, Tamil Nadu, India

\section{R Indra}

Professor and Head, Department of Conservative Dentistry and Endodontics, Ragas Dental College, Chennai, Tamil Nadu, India

\section{Premila Suganthan}

BDS, MSc in Laser Dentistry, Department of KP Toothcare, Diploma in Laser Dentistry, IALD and Aachen University, Chennai, Tamil Nadu, India 